بملة جامعة أم درمان الاسلامية

\title{
https://journal.oiu.edu.sd/index.php/oiuj
}

$2021 ; 17(1) ; 172-196$

https://doi.org/10.52981/oiuj.v33i1.787

ISSN: 5361-1858

\section{فاعلية الأنشطة الاتصالية للعلاقات العامة في تعزيز أداء المؤسسات المصرفية}

(بالتطبيق علي بنك السودان المركزي في الفترة من يناير 2020 إلي يناير 2021)

$$
\begin{aligned}
& \text { د.الرشيد داؤد ادم سليمان" ، د.المعز حموده علي حموده" } \\
& \text { * أستاذ مساعد - جامعة القرآن الكريم -السودان } \\
& \text { ** أستاذ مساعد جامعة بحري - السودان السران }
\end{aligned}
$$

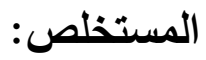

هدفت الدراسة إلي معرفة مدي فاعلية الأنشطة الاتصالية التي تقوم بها إدارة العلاقات العامة في تعزيز أداء بنك السودان المركزي وقد استخدم الباحث المنهج الوصفي التحليلي وتتكون عينة البحث من كل

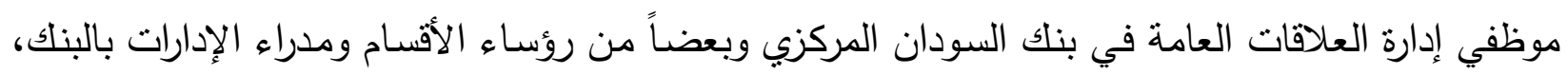

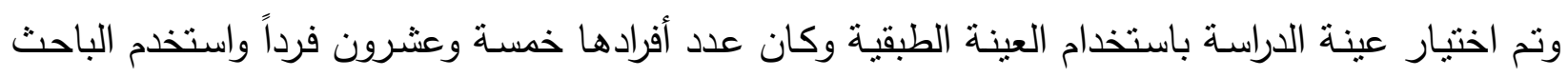
الاستبيان كأداة رئيسية في جمع البيانات والمعلومات ونم تحليل البيانات باستخدام برنامج SPSS ومن واندان أهم

1- أكدت نتائج الدراسـة أن الأنشطة الاتصـالية التي تقوم بها إدارة العلاقات العامـة داخل وخارج بنك فيك

$$
\text { السودان لها دور واضح وفعال في تعزيز أداء البنك. }
$$

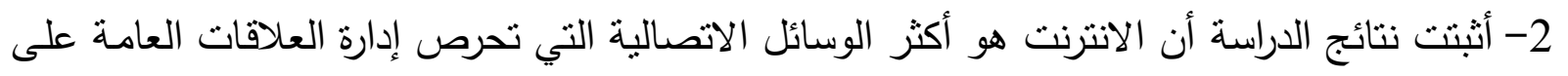

$$
\text { استخدامها. }
$$

3- وأوضــت نتـائج الدراسـة أن إدارة العلاقـات العامـة لا تقـوم بتتظيم لقـاءات دوريـة بـين العـاملين

$$
\text { والمسئولين في إطار تبادل المعلومات بصورة مباشرة في البنك. إنك. }
$$

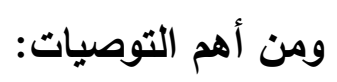

1- فصل إدارة العلاقات العامة من إدارة الخدمات وجعلها إدارة مستقلة قائعة بذاتها تنبع للإدارة العليا

$$
\text { للبنك. }
$$

2- إعطاء صـاحيات أكبر لإدارة العلاقات العامة حتى تساهم مـع الإدارة العليا في صنع القرار وحل

$$
\text { المشاكل والصعوبات والأزمات التي تواجه البنك. }
$$


فاعلية الأنشطة الاتصالية للعلاقات العامة في تعزيز أداء المؤسسات المصرفية- .الرشيد داؤد ادم سلمان ، المعز حموده علي حموده

3- توفير سلطات وصلاحيات لموظفين العلاقات العامة للاخول للمؤسسات الدولة والمؤسسات الخاصـة

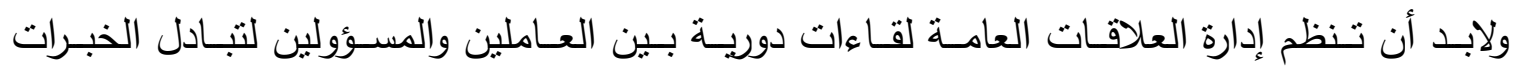

والمعلومات بصورة مبانشرة بينهم.

الكلمـات المفتاحيـة: العلاقـات العامـة - أنشطة العلاقـات العامـة - نشـأة وتطـور المصـارف في

السودان - بنك السودان المركزي

\section{ABUSTRACT}

The research aimed to know the effectiveness of public relations communication activities in emphasizing the performance of the banking institutions.

the researcher has used a descriptive methodology The research community consists from all public relations department workers and head of departments in the Bank The study sample was selected by used the stratified sample method and it is number was (25) individuals, The researcher has used a questionnaire as a main tool to know the researchers point of view the data was analyzed through the SPSS program and the most important result are:

1- The Result of the study said that public relations communication activities inside and outside the bank have effective role in development the central bank of Sudan.

$2-$ The result of the study confirmed that the internet is the most communication means that public relation used.

3- the study demonstrated that the administration of public relations not regulated meetings between workers and officials in the framework of exchange of information and experience directly in the bank.

The most important recommendations: -

1- Separate public relations department from management services and make it follow senior management of the bank.

2- Give greater powers to public relations management to participate senior management in making decision and find solutions for problems, difficulties and crises facing the bank. 
3- administration of public relations must regulate meetings between workers and officials in the framework of exchange of information and experience directly in the bank.

\section{مقدمة الاراسة:}

العلاقات العامـة هي الذراع القوي المسـاعد في تتفيذ خطط وسياسـات المنشـأة ولذا فإن العلاقات

العامـة تكتسب أهميـة خاصـة في القطاع المصـرفي الذي يعمل على نسـريع عجلـة التتميـة الاجتماعيـة والاقتصادية، نظراً للدور الحيوي الذي يمكن أن تقوم بـه العلاقات العامة في المصرف على مستوى دعم كيانه وتعزيز فرص بقائه واستمراره، فقد بدأت الإدارة العليا في المصـارف تعي وتدرك أهميـة القيام بهذا النشاط خاصة مع ما تتصف به الخدمة المصرفية من نمطية عاليه، حيث برزت نتيجة لذلك اعتبارات أخرى تحكم اختبار الفرد للمصرف الذي يتعامل معه وظهرت اعتبارات كنوعية الخدمة التي يقدها، وطريقة التعامل

$$
\text { مع الجمهور (عجوة ،1999،ص11). }
$$

مشكلة الاراسة:

يعتبر نشاط العلاقات العامة من الأنشطة التي تواجه بعض المشكلات المرتبطة بمفهومها ووظائفها وأساليب ممارستها والنظرة القاصرة إلى فاعليتها إذن فما سبب هذه المشكلات التي تحد من نشاطها أهي عدم اهتمام الإدارة العليا بها أم إهمال جانب البحوث العلمية أم بسبب عدم توفر وسائل الاتصال الحديثة ولمعرفة كل ذلك كان لا بد من الوقوف على هذه المشكلات وغيرها وفقاً لرؤى علمية منهجيه واضحة وكان هذا منطلق لدراسـة مسحية وصفيه تحليليه عن فاعليـة الأنشطة الاتصـالية للعلاقات العامـة في تطوير أداء المؤسسات المصرفية بالنطبيق على بنك السودان المركزي.

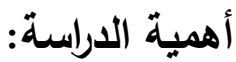

وتكمن أهمية هذه الدراسـة في التعرف على مدى فاعلية الأنشطة الاتصـالية للعلاقات العامة في تطوير أداء المصارف ونقاط القوة لتعزيزها ونقاط الضعف لتقليلها ورفع نتائج كل ذلك للإدارة العليا، وتأتي أيضاً أهمية هذه الدراسة من أنها جهاً متواضع من الباحث يساهم به في دعم الجهود البحثية للمزيد التوسع 
في مجال العلاقات العامـة. وبالرغم من تشـابه معظم المصـارف في تقديم الخدمات المصرفية (الأسهر القروض - دعم وتمويل - بعض الششروعات.. الخ).

إلا إن أسـاليب تقديم هذه الخدمات تختلف من مصرف إلى آخر وهذا يجعل دور العلاقات العامة أكثر أهمية في ملاحقة هذه التطورات والاحتفاظ بثقة العملاء والتطلع لكسب عملاء جدد.

أهداف الدراسة:

1. التعـرف على فاعليـة ودور الأنشــة الاتصـالية للعلاقـات العامـة فـي تعزيـز أداء المؤسسـات

المصرفية.

2. معرفة ما إذا كانت إدارة العلاقات العامة تقوم بتغطية الأنشطة الاتصالية لبنك السودان المركزي أم

3. التعرف علي نوع الوسائط الاتصالية التي تستخدمها العلاقات العامة في البنك.

4. لفت انتبـاه المسؤولين في القطاع المصـرفي إلى أهمية الدور الذي يمكن أن تقوم بـه الأنشطة الاتصالية للعلاقات العامة في المساهمة في تطوير أداء البنك.

5. معرفة مـا إذا كانت إدارة العلاقات العامـة تنظم لقاءات دوريـة بين العاملين والمسؤولين في إطـار

تبادل المعلومات بصورة مباشرة في البنك.

أسئلة الدراسة:

1 / ما أهمية دور العلاقات العامة في بنك السودان المركزي؟

2/2 ما الأنشطة الاتصالية التي تقوم بها إدارة العلاقات العامة في البنك؟

3/ ما الوسائل والأنماط الاتصالية التي تستخدمها إدارة العلاقات العامة لتحقيق الأهداف

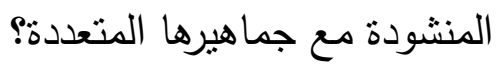

4/ هل تتظم إدارة العلاقات العامة لقاءات دورية بين العاملين والمسؤولين في إطار تبادل المعلومات

بصورة مباشرة في البنك؟ 
منهج الاراسة: استخدم الباحث المنهج الوصفي والأسلوب المسحي.

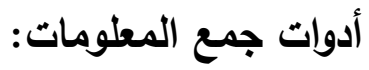

الاستبانة: ولقد تم استخدامها لجمـع المعلومـات من مجتمـع البحث الأصلي المتمثل في العاملين في إدارة العلاقات العامة بالبنك

مصطلحات ومفاهيم الورقة: قام الباحث بتعريف بعض المصطلحات الواردة في البحث وهي: الفاعلية:لغة هي مقدرة الثيء على التأثير .

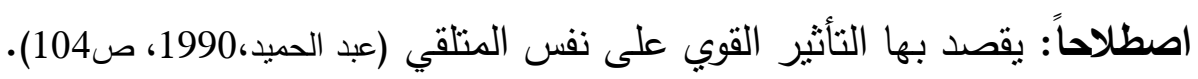
الأنشطة الاتصـالية: وهي مجموعة من البرامج المختلفة والمتتوعة بأثنكال عديدة تقوم بها إدارة العلاقات العامة وتقوم بتوصيلها لجمهوريها (عجوة ،2004، ص24). العلاقات العامـة: اصطلاحاً: تطلق على جمهور المنظمة والعمليات التي تقوم بها هيئة أو مؤسسة لتنظيم العلاقات بينها وبين جمهور العاملين معها بهدف تحقيق علاقات ايجابيه مـع هذه الجماهير، وتقوم بهذا إدارات متخصصــة تعنـى عنايـة فائقــة لاسـتخدام وسـائل الاتصــال والإعــلام المتتوعـة لتحقيـق مهمتهـا. (ثلبي،1989،ص140) التعزيز

تعزيز : مصدر عزز ، يعزز، تعزيزا، نقول عزز فلانا فلان أي قواه وشده ودعمه وجعله عزيزا، أمده، أيده المؤسسـات المصـرفية: مؤسسـة ماليـة تتعاطى الإقراض والاقتراض فتستمر الودائع والأموال ويقال أيضـا بنأك) (www.wikapdia.com)

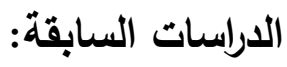
الاراسة الأولى:

الباحث: صالح بابكر الحاج ( دور العلاقات العامة في تطوير المصارف الإسلامية ) رسالة دكتوراه غير منشورة جامعة أم درمان الإسلامية كلية الإعلام 2007م.

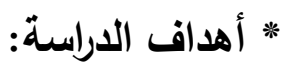
تهدف هذه الدراسة بشكل أساسي إلى توصيل نتائج تساهم في تطوير المصارف الإسلامية من خلال تفعيل دور العلاقات العامة في المصرف ويرتبط هذا الهدف بأهداف فرعيـة أهمها تحسين الصورة 
الذهنيـة للمصرف عند عملائه، تطوير المصرف من خـل زيـادة المكاسب الماديـة للمصرف وقدرته على التتافس. المـنهج المسـتخدم في الدراسـة:اسـتخدم الباحث منهج المسـح الإجتمـاعي وهو طريقة الاتصـال بمفردات المجتمع مباشر أو غير مباشر عن طربق صحيفة الإستبانة كما أستخدم الباحث المنهج الوصفي التحليلي لوصف واقع الحال لمجتمع الدراسة.

\section{نتائج الدراسة:}

1. إن التزام موظف المصـرف بالبشاشـة وحسـن اسـتقبال العمـلاء والقيـام بزيارتهم،وعدم تجـاهلهم وتسـهيل ومجانية عملية الاتصال بالمصرف وتقديم المكافآت والحوافز يؤدي إلى جذب العميل. 2. أثبتت الدراسة أن إرضاء العميل واستخدام أدوات ووسائل الترويج لنشر الوعي المصرفي وابتكار مشاريع وخدمات جديدة تستقطب العمـلاء إلى زيادة المكاسب المادية للمصرف وسرعة وجود الخدمة المصرفية كما إن بشاشة وحسن الاستقبال وإرشاد العميل يؤدي إلى إرضائه. الاراسة الثانية:

الباحث: عبدالرحمن محمد بن عوف (العلاقات العامـة ودورها في تكوين الوعي المصرفي) رسالة ماجستير غير منشورة جامعة أم درمان الإسلامية، كلية الإعلام،2007م. أهداف الاراسة: 1. الوقوف على مفهوم العلاقات العامة وأهميتها. 2. التعرف على أهداف العلاقات العامة ووظائفها. 3. التأكد على أهمية الممارسة العلمية الصحيحة للعلاقات العامة. 4. تهدف الدراسة كذلك للتعرف على دور العلاقات العامة في نشر الوعي بسياسات المصرفية التي يصددها البنك المركزي وخلق وسائل العلاقات في التوعية المصرفية. 
المـنهج المسـتخدم في الدراسـة: استخدم الباحث المنهج الوصفي التحليلي في وصف الظواهر

وتحليل البيانات والحقائق.

نتائج الدارسة:

1. يجب ضم الإعلام والاتصال إلى قسم العلاقات العامة وترقيع القسم إلى إدارة يتولى إداراتها شخص بدرجة مدير إدارة انتداب إعلاميين مقتدرين بالاقتصاد والعمل المصرفي. 2. مراعاة التخصص عند استيعاب العاملين بالعلاقات العامـة لأنـه يساعد على الفهم الصحيح لدور العلاقات العامـة وإسـهاماتها، مـع زيـادة عدد العاملين بالعلاقات العامـة من تخصصـات الإعـلام المختلفة بوظائف العلاقات العامة (البحوث - التخطيط - الاتصال - التقويم).

\section{علاقة الاراسات السابقة بموضوع الورقة:}

تتاولت الدراسـة الأولى دورة العلاقات العامـة في تطوير المصـارف السودانية الإسـلامية وعلاقتها بالدراسة الحالية أن كلا الدراستان تهدفان إلى معرفة الدور الذي تقوم بـه برامج وخطط العلاقات العامة في تطوير أداء المصارف وركزت الدراسة العالية في معرفة الأنشطة الاتصالية في تطوير أداء المصارف (بنك السودان المركزي) واتفقاً أيضاً في استخدامهما للمنهج الوصفي التحليلي وأضافت الدراسة الحالية الأسلوب المسحي.

أما الدراسة الثانية والحالية اهتمتا بمعرفة دور العلاقات العامة وأنشطتها في تطوير أداء المؤسسات المصرفية وأغفلت الدراسـة السـابقة عن التركيز على الخطط والبرامج والبحوث باعتبارهـا من أهم عوامل التطوير وركزت الدراسة الحالية على معرفة فاعلية الأنشطة الاتصالية في تطوير أداء المؤسسات المصرفية. الإطار النظري:

العلاقات العامة

إذا كان اصطلاح العلاقات العامة قد أصبح معروفاً على نطاق واسع خلال العشرينيات من القرن السابق إلا أن مفهوم العلاقات العامـة ظل يحيط بـه الغموض في والولايات المتحدة الأمريكية حتى مجيء الخمسينيات، كما انه لا يزال بعاني بعض التفسيرات الخاطئة في أجزاء أخرى من العالم حتى الآن، ورغم أن 
تعبير الثئون العامة قد بدأ ينتشر الآن كجزء من وظيفة العلاقات العامة إلا أنه استعمل في بعض الأوقات كمرادف لها إلى أن جاء عام 1952م حينما حث الرئيس الأمريكي دوايت ابزدهاود رجال العمال على المشاركة في الأنشطة السياسية، بعد أن تطورت الصناعة بشكل هائل وأصبح لها تأثثر كبير على المجتمع الأمريكي وبعد ذللك بعامين أنشئ مجمع الثئون العامة (Public Affairs Council) كمنظمة رسمية مهمتها تدريب مديري الأعمال على برامج الشئون العامة وقد نشطت هذه الحركة وانضم إليها عدد كبير من الثركات الأمريكية ويقدر عدد الثركات التي تهتم ببرامج الثئون العامة في والولايات المتحدة الأمريكية الآن بأكثر من خمسمائة شركة وحتى الآن لا يوجد تحديد دقيق لمفهوم الثئون العامة ولكن كان من الواضتح انه ينص على المسئوليات الاجتماعية لأي منظمة إزاء الجمهور العام والمشكلات العامة في المجتمع وهو يدخل في إطـار العلاقات العامـة ويندرج تحت إثنراف إدارتها وقد خصص لها في بعض الثـركات قسم كامل متخصص تحت إثراف إدارة العلاقات العامـة يصل عدد العاملين فيه إلى أكثر من خمسين في الثركات

$$
\text { الكبرى بينما لا يتجاوز العشرة في معظم الثركات الأخرى (عجوة ، } 2004 \text { ، ص20). }
$$

وقبل أن نعرض وجهات النظر المختلفة في تحديـ مفهوم العلاقات العامـة، نحـاول تحليل هذا

$$
\text { المصطلح المكون من كلمنين هما علاقات وعامة. }
$$

1. العلاقات: وتعني "حصيلة الصلات والاتصالات التي تتوفر بين المنظمة والجماهير المتعاملة معها. 2. عام: ونعني به عموم وكافة الجماهير المختلفة التي يتصل عملها أو ترتبط مصالحها ونشاطاتها، وبذلك فإن العلاقات العامة اصطلاحاً هي مجموعة الاتصالات التي تحدث بين المنظمة ومختلف الجماهير

$$
\text { المتعلقة بها (عبد الحارث، 2000، ص30). }
$$

وفيما يلي نورد أهم التعاريف الخاصـة بالعلاقات العامـة عرفها المعهد البريطاني للعلاقات العامـة

بأنها "الجهود المقصودة والمخططة والمستمرة لإقامة واستمرار الفهم المتبادل بين أي منظمة وجماهيرها. وقد توصلت جمعية العلاقات العامة الدولية إلى التعريف التالي "العلاقات العامة هي وظيفة الإدارة المستمرة والمخططة والتي تسعى بها المؤسسات والمنظمات الخاصـة والعامة لكسب تفاهم وتعاطف وتأييد الجماهير التي تهمها والحفاظ على التأييد وذلك من خـل قياس اتجاه الرأي العام باستمرار هذا التعاطف والتفاهم لضمان توافقه قدر الإمكان مع سياساتها وأنشطتها وتحقيق المزيد من التعاون الخلاق والأداء الفعال للمصالح المشتركة باستخدام الإعلام الثامل المخطط (إمام ، 1958، ص6). 


\section{وعرف رويينسون العلاقات العامة:}

بأنها: علم اجتمـاعي سلوكي وتطبيقي بعد إجراء دراسـة على أكثر من 100 شـركة بأنها تلك الوظيفة التي تتضمن قياس وتقويم اتجاهات الجماهير النوعية المختلفة والتي لها علاقة بالمؤسسة ومساعدة الإدارة في تحديد الأهداف الراميـة إلى زيـادة التفـاهم والوفـاق بين المؤسسـة وجماهيرهـا وتحديـد سياسـات المؤسسة وقدراتها وتحقيق التوازن والتكيف بين أهداف ومصالح واحتياجات الجماهير النوعية التي لها صلة بالمؤسسـة وتخطيط وتتفيذ البرامج الاتصـالية والاجتماعية التي تستهدف كسب تفاهم الجمـاهير النوعيـة

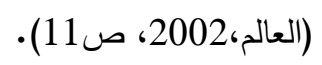

ولقد مرت العلاقات العامة الحديثة بنطورات عديدة حتى وصلت إلى ما هي عليه الآن خاصة بعد الحرب العالمية الثانية حيث أتيحت فرصة جديدة لاستعمال العلاقات العامة نتيجة ظهور مخترعات جديدة وتطور وسائل الإعلام والانفتاح الاقتصادي من أهم هذه التطورات.

$$
\text { 2/ } 1 \text { زيادة عدد المنشآت التي تنتخدم العلاقات العامة. }
$$

3/ ظهور الهيئات المهنية لترفع من مستوى العلاقات العامة وتتظيم دراستها والأبحاث الخاصة بها.

4/ زيادة عدد الكليات التي تقوم بتدريس العلاقات العامة والمواد المتعلقة بها.

ولقد شهدت سنة 1948م مولد هيئتين كبيرتين لتتظيم العلاقات العامـة ودراستها وتسطير دستور أخلاقي يسـير عليـه جميـع المشـتغلين بههـا هــا: العلاقـات العامـة البريطـاني وجمعيـة العلاقـات العامـة

$$
\text { الأمريكية. (خير الدين، ص42) }
$$

وقد ساعدت الاختراعات الحديثة والتكنولوجيا المتطورة في وسائل الاتصال مثل الراديو والتلفزيون بل الأقمار الصناعية (والتي وصلت إلى حوالي ثلاثة ألاف قناة إرسال واستقبال تغطي العالم كله) على اتساع مجال العلاقات العامة، وتطبيقاتها في مختلف أنشطة العمل بل وسرعة انتقال الآراء والأفكار من بلد لأخر

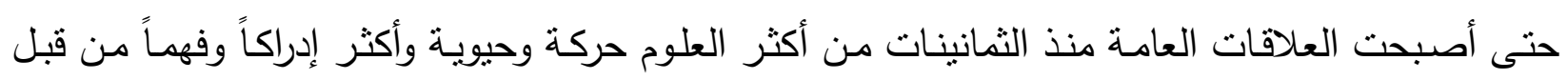
الجماهير عما كانت عليه في الأربعينات والخمسينات (المصري،2000،ص5). 
إن مهنة العلاقات العامة تتطور كاستجابة وتوقع للاتجاهات السائدة العالمية والقومية والمحلية مما يفرض على القادة والعاملين في العلاقات العامة - خاصة في العالم العربي والدول النامية. مسايرة التقدم في التكنولوجيا الحديثة والتطورات التكنولوجية في مجال الاتصـال وتقنية المعلومات

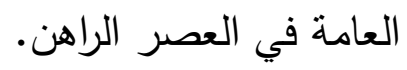
وإن لم يحدث ذلك كما يؤكد الخبراء فسيكون البديل أنثكال مهجورة من العلاقات العامة عفى عليها الزمن في ممارسة وإساءة في خدمة المؤسسة وجماهيرها. الاتصال في العلاقات العامة:

تتعدد وسائل الاتصال المستخدمة في العلاقات العامة التي تقوم إدارة العلاقات العامة في المنظمة بالإشراف على إعدادها وتتفيذها ومن تلك الوسائل: أولاً: النشرات الخاصة التي تصدرها المنظمة: تعثبر هذه النشرات من وسائل الاتصال بالكلمة المقروءة وهي وسائل اتصال خاصة حيث نستهدف جماهير معينة، كما أن موضوعاتتا تتطلب تغطية مكثفة فقد تصدر المنظمة صحيفة أو مجلة خاصـة بها تتضمن عدداً من المواضيع والمعلومات التي تهم جمهور المنظمـة بهدف خلق تأثنر معين في اتجاهات ومواقف وأراء ذلك الجمهور إزاء سياسات المنظمة وإنجازاتها وخططها (صالح، 2004، ص 224). ثانياً: الاتصال الهاتفي: وهو نوع من الاتصـال الثخصي المباشر في مجال العلاقات العامـة وتبرز أهميته في إن الكلمة المسموعة والمباشرة من الثخص يكون لها تأثيراً قوياً علي الثخص الآخر الذي يتم التخاطب معه، من الكلمة المكتوبة الصادرة عن نفس الثخص، كما أن نكلفة استخدام هذه الوسيلة بسيطة ويعتبر الهاتق وسيلة سريعة للاتصال بين المسئولين بالمنظمة وجماهيرها الخاصـة عاملين وعملاء وموردين ومستثمرين وغيرهم، ومن المهم الإشارة إلي ضرورة مراعاة الحديث الهاتفي التي تكلف نجاح المكالمة في التأثنر في نفسية المتكلم معه (جرادات، 2009م ص 134). ثالثاً: الاجتماعات الدورية: وهي وسيلة من وسـائل الاتصـال الثخصسي والمباثـر كالاجتماعات بين رئيس الجامعة وأعضـاء

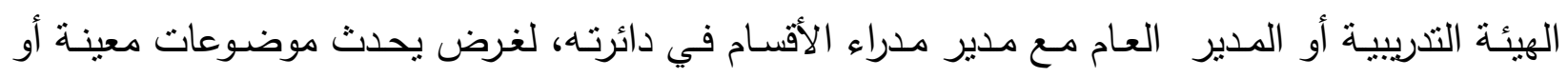


اجتماعات بين رجال الإدارة والعاملين أو بين ممثلي المنظمة وممتلي المستهلكين أو الموردين أو المستثمرين أو غيرهم، وتتيح هذه الوسيلة للاتصـال الفرصـة لتعرف علي مطالب واحتياجات الجمهور الخاص وإمداده بكافة المعلومات والحقائق التي تتقصه و إتاحة الفرصة له كي يعبر عن رأيه ووجهات نظره بشأن سياسات وبرامج وانجازات المنظمة بما يتيح الفرصة لتعديلها بما يتفق مع اتجاهات الرأي العام للجههور وكذلك توفير مناخ للاستجابة الثخصية الفورية (الصوفي ، ص19). رابعاً: الكتيبات:

يعتبر الكتيب من أكثر أساليب الاتصال الجماعي تأثثراً وهو يتضمن عادة كافة المعلومات التي يهتم عمال كل المنظمة التعرف عليها لتبديد مخاوفهم، فهو بمثابة مرجع لا غني عنه يجنب العمال الاعتماد علي معلومات أو مصادر غبر موثوق بها. ولهذا يضم غالباً الموضوعات الآتية: • ملخص عن سياسة المنظمة. • • الاحتياطات الصحية وأساليب الأمن الصناعي. • • المساعدات والرعاية الاجتماعية التي توجهها المنظمة للعاملين.

$$
\text { • • مستوي المكافآت ونظم الترقي (صالح ،بهت ،ص 224). }
$$

خامساً: الأحاديث والخطب العامة:

وهذه الوسيلة جيدة للاتصال بالرأي العام إذا بحثت خطط لها تخطيطاً سليماً و من حيث الضرورة لا يجوز عقد المؤتمر إذا لم يكن الاستغناء عنه بوسيلة أخري ومن حيث الوقت فوقوع المشكلة في المؤسسة يهتم بها الجمهور أما وقوع مشكلة عامة تستطيع المؤسسة أن تساهم في حلها، ومن حيث الثكل فالتحدث عن المشكلة في مكان وجودها أو وقوعها بالكلمة والصورة يؤثر في الرأي العام أكثر من التحدث عنها في المكاتب و من حيث طريقة تتاولها فالأسلوب الحواري الذي يعتمد علي الجمل القصيرة يجذب الإنسان أكثر من الأسلوب المتراسل غير الحواري الذي يدفع بالقارئ إلي الملل. سادساً: الأحاديث أو الخطب العامة:

إن الكلمة المنطوقة أو الثفوية مازالت أكثر أثنكال الاتصال قوة وفعالية، لهذا فالحديث أو الخطبة العامـة مـن الأدوات الرئيسية لممارس العلاقات العامـة و الأحاديث والخطب العامـة وسيلة اتصـال مباشـر 
مسموعة كأن يقوم أحد مسئولي المنظمـة بالتحدث أو الخطابـة أمـام العاملين في المنظمة أو مستهلكين أو المساهمين، وفي الحديث يوضتح المتحدث سياسـة المنظمة وأهدافها وبرامجها و انجازاتها ويحاول أن يلقي تأييداً ومؤازرة الجمهور الذي يخاطبه، وقد يكون الهدف من الحديث أو الخطبة محاولة نفي إثـاعة أو إزالة

$$
\text { فكرة سيئة عن موقف المنظمة أو انجازاتها (عبد الحارث ، 2000، صمات3و). }
$$

سابعاً: الدعوات العامة والزيارات الإعلامية:

إن الدعوة العامـة أو المفتوحسة يمكن أن تخدم في أغراض كثيرة باعتبارهـا أدوات مهمـة للعلاقات العامة بالمجتمع حيث يتم من خلالها إعلام العملاء والموردين والمستهلكين ورجال الصحافة كيف تعدل المنظمـة علي الطبيعـة وهو أمـر يكفل اندماجهم مـع المنظمـة ومعايشتهم لواقعها وارتبـاطهم بها وشعورهم

$$
\text { ثالالتثماء إليها (بن عوف 2007م، ص 13). }
$$

وهي وسيلة تستخدم الاتصال بالعام لينو حتى المستهلكين والموزعين والوكلاء وهي رسالة يستطيع محررها التحكم في محتواهـا والتخطيط لذلك المحتوي دون انفعال، ولكن قد لا تتفع هذه الوسيلة إن كان المخاطب أمياً وقد لا يدرك المخاطب مفهوهها، وقد يفسرها تفسيراً مغايراً لمعانيها مادام بعيداً عن مرسلها

$$
\text { تاسعاً: المعارض،2007م،ص 31). }
$$

وتعد من القنوات الاتصال الجمعي المهمة التي تستخدم بشكل مؤثر من قبل أجهزة العلاقات العامة والمعرض طريقة أو وسيلة لعرض فكرة أو التعبير عنها ويتم ذلك بترتيب الأجسام وخاصـة الحي منها نرتيباً مقصوداً علي وفق خطة موضوعه.

والمعـرض يشـكل صـورة مجسمة عـن نشـاط المنظمـة، بترتيـب وتعليم الجمهـور بـدور المنظمــة

$$
\text { الاجتماعي والخدمات التي تؤديها في هذا المجال }
$$

تسـتخدم إلـي جانـب المنتجـات المعروضـة النــاذج والملصـقات، والمجســات الصـغيرة الفولــرات

$$
\text { وغيرها. (سلطان، بت، ص 199). }
$$




\section{عاشراً: الإذاعة الداخلية وإلتلفازية المغلقة:}

وهاتان من وسائل الاتصال الداخلي، تستخدم لأغراض عديدة منها إذاعة برامج الموظفين، حيث يتخ

إعلام الموظفين ببرامج جديدة للخدمات أو المميزات الإضافية التي أدخلتها المنظمة (الحاج ،2007م،ص 34).

\section{إحدى عثر : البريد الإكتروني:}

يعتبر البريد الإكتروني من أهم تطورات خدمات الإنترنت إذا تمكن المستخدم من الاتصال بصورة

متبادلة مع أي شخص في أي مكان مهما بعدت المسافة، حيث أصبحت المؤسسات تستخدم مواقع البريد الإككتروني لتواصل مع عملائها لذلك لقد أصبح البريد الإكتروني من الوسائل التي نستخدمها العلاقات العامة في الاتصال.

استطلاعات الرأي بالبريد الإلكتروني:

ويعتمد عليها في جمع البيانات من الثرائح السكانية المستهدفة ويعتبر بديلا للاستطلاعات الورقية.

\section{نشأة وتطور المصارف في السودان}

بدأ النظام المصرفي في السودان البداية الطبيعية التي سلكتها معظم الدول النامية التي حصلت على استقلالها من الدول المستعمرة فكانت بداية نشأتها بفتح أول مصرف في السودان عام 1903م بافتتاح فرع للبنك العثماني عام 1949م وبنك مصر عام 1953م. ولقد تميزت هذه الفترة أيضاً بظهور بنك الكريدي ليونيه عام 1959م وأيضاً تميزت هذه الفترة بسيطرة فروع البنك الأجنبية على العمل المصرفي في السودان ولم يكن لها إسهام واضح في عمليات التتمية الاقتصادية التي انتظمت البلاد بعد الاستقلال، ولقد ظل دور البنوك التجاريـة قبل إنشـاء بنك السودان عام 1960م مقصـوراً على توفير الخدمات والتمويـل المصـرفي للثـركات الأجنبيـة التي كانت تشيطر على النشـاط الاقتصادي في البلاد وقد أدى ذلك إلى سيطرة البنوك التجارية على الأرصدة الأجنبية والتركيز في عملها على القروض قصيرة الأجل ذات العائد السريع والمجزي إذ كانت تلك القروض الني تمثل نسب عالية من عملها المصرفي. 
كما أن معظم القروض التي استخلت لتمويل التجارة الخارجيـة يتم توفيرها للثـركات الأجنبيـة والتي كانت رئاستها بالخارج (عباس، 2003، صرئ101)

إن هيكل الجهاز المصرفي في السودان شأن الأجزة المصرفية في الدول النامية، هو هيكل بسيط يتكون من ثلاثة أنواع أساسية بإضافة إلى الودائع بمكاتب البريد وغيرها، والتي تعتبر بنوكاً بالمعنى المفهوم وهي على النحو التالي: 1/ البنك المركزي، والذي يقع على قمة الجهاز المصرفي ويسيطر عليه. 2/ شبكة البنوك التجارية.

3/ والنوعان الأولان معاً بالإضـافة إلى الوظائف الأخرى مسؤولة عن خلقة وتصنيع إجمالي الإمداد بالنقود والقوة الشرائية. أمـا المجموعـة الثالثنة مـن البنـوك في مخصصـة للقيـام بـدور التتميـة والتطـوير في المنـاطق والقطاعـات المخصصة (السيد، 2005، ص313).

تم إنشاء البنوك المتخصصة في أواخر الخمسينات وأوائل فترة التسعينات حيث تم إنشـاء البنك الزراعي السوداني عام 1959م وتلاه البنك الصناعي والبنك العقاري في مطلع الستينات، ولقد كان القرض الأساسي من تأسيس هذه المصارف إعطاء عناية أكبر وتوفير التمويل اللازم للقطاعات التي أهملتها البنوك التجارية الأجنبية وعلى رأسها القطاع الزراعي الذي يمثل رأس رمح الاقتصاد السوداني، كما تم في مطلع الستينات إنشاء أول بنك سوداني بمساهمة من القطاع الخاص السوداني كتجربة رائدة في ولوج العمل المصرف من قبل الرأسمالية الوطنية ولقد أسهم البنك بدوره الفعال خـلال عقد الستينات في دفع تطور العمل التجاري الوطني وفتح آفاق جديدة أمام رجال الأعمال الوطنيين من المصدرين والمستوردين الذين كانوا يعانون من التتافس الحاد من قبل الثركات الأجنبية العاملة في القطاع التجاري عام 1970م الذي انتهج نهجاً اشتراكياً تم بمقتضاه تأميم ودمج بعض فر وع البنوك الأجنبية 1970م مما أدى إلى ابتعاد عدد كبير من المتعاملين مع البنوك وعلى الأخص الثركات الأجنبية التي كانت عاملة آنذالك وتوقفت أعمالها بالسودان لم تدم طويلاً إلا أنها تركت آثار سـالبة على مجمل مسـار الاقتصـاد السوداني وأثارت الخوف والتردد في التعامل مـع المصارف الأمر الذي أدى إلى سلبية وعدم فعالية الجهاز المصرفي في ذلك الوقت، ثم صدر قانون تتظيم 
البنوك والادخار عام 1973م وشهر منتصف السبعينات الانفتاح الاقتصـادي كرد فعل إيجابي لسياسة تأميم

$$
\text { البنوك التي أضرت بموقف الاقتصاد السوداني. (الخضري،1410، صات } 7 \text { ) }
$$

نشأة وتطور بنك السودان:

ترجع نشأة البنوك في السودان إلى بداية الحكم الثنائي وذلك بعد توقيع الاتفاقية بين بريطانيا ومصر والتي تلتها بعض النظم الحديثة في السودان في المجالات المختلفة كبرامج التعليم والصحة والتجارة والزراعة والتي ساعدت في خلق بيئة تلاعم التطور الاقتصادي والاجتماعي حيث ظهرت مدن جديدة وبدأت زراعة محاصيل نقدية وتجارة في نطاق ضيق.

وشعر الحكام آنذاك بالحاجـة لوجود مصـارف لمقابلة هذا التطور وذلك لخدمة مصـالحهم ولحفظ ودائع الإداريين والفنيين من البريطانيين والمصريين وغيرهم من الأجانب حيث افتتاح فرع البنك الأهلي المركزي مثل حفظه لودائع الحكومة (بنك الحكومة) حيث ازدهرت التجارة بالبلاد أكثر وتبع ذلك عدة فروع

$$
\text { لبنوك أجنبية (موسي، 1994، ص50). }
$$

وعندما نـال السودان استقلاله برزت الحاجة لوجوده ولتحقيق ذلك، في أواخر ديسمبر 1956م تم تشكيل لجنة من ثلاثة خبراء من بنك الاحتياطي الفيدرالي الأمريكي لعمل دراسة مستفيضة في هذا الثنأن والنظر في إمكانية إنشاء بنك مركزي بالسودان. بعد أن فرغت اللجنـة مـن الدراسـة ورفعت توصياتها تبـع ذلك إصـدار قـانون بنـلك السودان لسـنة 1959م وفتح أبوابـه للعمل في فبراير 1960م كهيئة قائمسة بذاتها لها شخصيتها الاعتباريـة وصفة تعاقديـة وخاتم عام يجوز لها التقاضي باسمها بصفتها مدعية أو مدعى عليها حيث حددت المادة (5) أغراض البنك في الآتي:

تكون الأغراض الرئيسية للبنك تتظيم إصدار أوراق النقد والنقود المعدنية والمساعدة في تتمية نظام مصرفي ونظام للنقد والائتمان في السودان والعمل على استقرار بغرض تحقيق التتمية الإقتصادية في البلاد على نحو منتظم ومتوازن وتدعيم الاستقرار الخارجي للعملة وأن يكون مصرفاً للحكومـة ومستشاراً لها في لي بعري

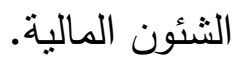
ولذلك يكون هذا القانون قد مكن البنك من القيام بدوره المنوط به حسب الوظائف الآتية: 
إصـدار العملـة والورقيـة والمعدنيـة وحفظ إحصـائيات الأجهزة الحكوميـة ووحدتها في إدارة الدين الخـارجي والداخلي وإدارة السياسات النقدية والبحوث والتخطيط الخاص بالجهاز المصرفي وتتميته وتطويره وأن يكون بنك البنوك وذلك بالقبام بحفظ احتياطات البنوك وهو بمثابة المقرض الأخير لها كما يقوم بإدارة عمليات

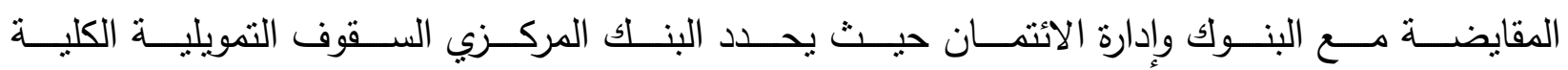
والغطائية.(موسي،1994،ص50).

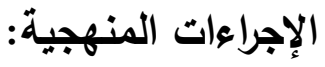

أولاً: منهج الدراسة: استخدم الباحث المنهج الوصفي باستخدام الأسلوب المسحي. مجتمع الاراسة: يتكون مجتمع الدراسة من جميع الموظفين والعاملين في بنك السودان المركزي.

عينة الدراسة:

وقد استخدم الباحث العينة الطبقية حيث قسم فيها المجتمع إلى طبقات وذلك بعد الدراسة الواعية للمجتمع وتعتبر هذه العينة أكثر دقه من العشوائية إن عينة هذه الدراسة تضم جميع العاملين بالعلاقات العامة وبعض مدراء ورؤسـاء الأقسام الإدارات الأخرى داخل البنك، وذلك لتعرف على مدى فاعليـة الأنشطة الاتصـالية للعلاقات العامة والى أي مدى ساهت هذه الأنشطة في تعزيز وتطوير هذه المؤسسة. أدوات جمع البيانات:

الأدوات الثانويـة: اعتمد ت هذه الدراسة على بعض الأدوات البحثية المتمنلة في جمع المعلومات والبيانات وهي المراجع العلميـة، والدراسـات المختصـة، من كتب ومراجع ومعاجم ودوريـات ومجـلات ورسـئل علميـة ومقابلات. الأدوات الأولية: اعتمد الباحث على: أ/ الاستبانة: وهي استخدمت كأداة رئيسة لجمع المعلومات والبيانات عن عينة البحث، تم تصميم استمارة الاسنبيان وفقا لأهداف وتساؤلات الدراسة، وبعد تحكيمها تم توزيع عدد 28 صحيفة على العينة المبحوثة تم جمعها واستبعد الباحث عدد 3 صحيفة تالفة ليصبح العدد الكلي (25) صحيفة تم رصدها وتحليلها عبر برنامج الحزم الإحصائية للعلوم الاجتماعية (SPSS). 
أولاً: البيانات الأساسية

\section{عرض وتحليل البيانات ومناقشتها}

جدول رقم (1) يوضح نوع المبحوثين

\begin{tabular}{|c|c|c|}
\hline النسبة المئوية & التكرار & النوع \\
\hline$\% 88.0$ & 22 & ذكر \\
\hline$\% 12.0$ & 3 & أنتى \\
\hline$\% 100.0$ & 25 & المجموع \\
\hline
\end{tabular}

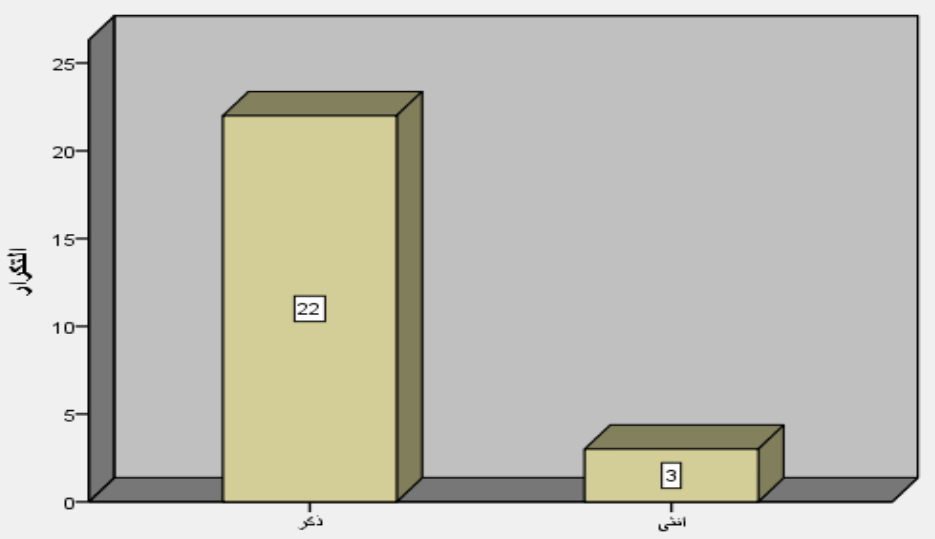

يتضـح من الجدول رقم (1) والرسم البياني أعـلاه أن معظم أفراد العينة المبحوثة الذين بمارسون العمل في إدارة العلاقات العامة ببنك السودان ذكور حيث بلغت نسبتهم (88\%) من أفراد العينة وان 12\% منهم إناث وهذا دليل واضـح على تفوق الذكور بالاهتمام بالعلاقات العامـة وقد سـاهم هذا على تطور أداء إدارة العلاقات العامة.

جدول رقم(2): يوضح المؤهل العلمي

\begin{tabular}{|c|c|c|}
\hline النسبة المئوية \% & التكرار & المؤهل العلمي \\
\hline$\% 16.0$ & 4 & ثنانوي \\
\hline$\% 68.0$ & 17 & جامعي \\
\hline$\% 16.0$ & 4 & فوق الجامعي \\
\hline$\% 100.0$ & 25 & المجموع \\
\hline
\end{tabular}


فاعلية الأنشطة الاتصالية للعلاقات العامة في تعزيز أداء المؤسسات المصرفية- الرشيد داؤد ادم سليمان ، المعز مهوده علي مهوده

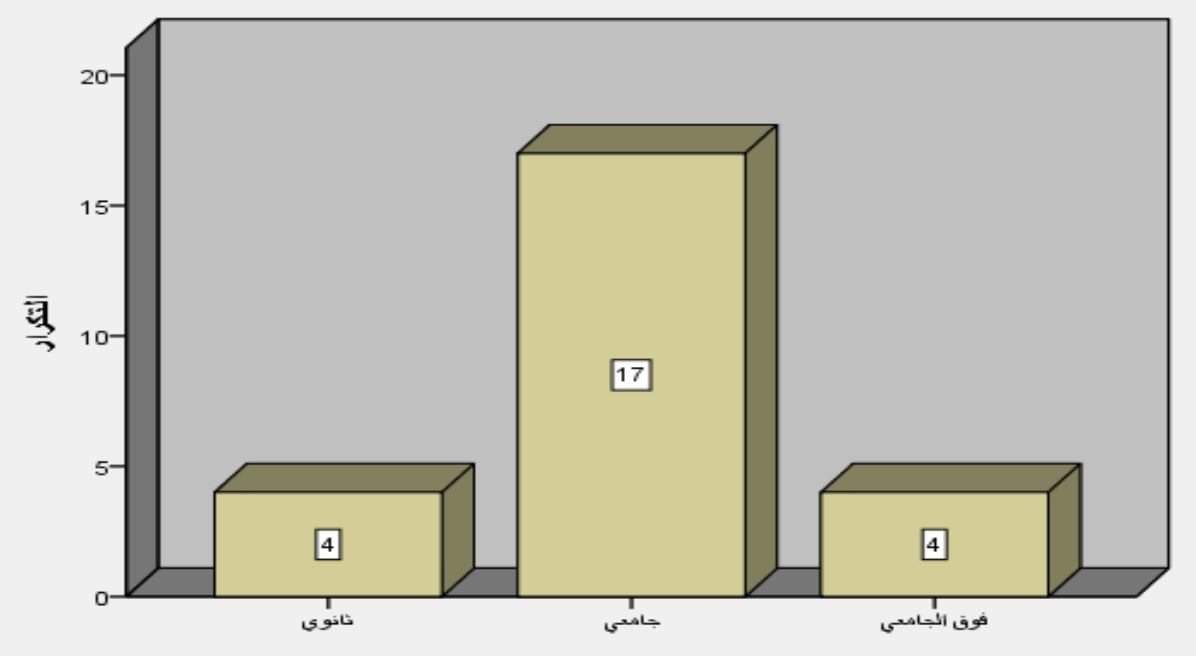

يتضح من الجدول رقم ( 2) والرسم البياني أعلاه أن أغلب أفراد العينة المبحوثة مستواهم التعليمي جامعي حيث بلغت نسبتهم (68\%) وهذا يدل على أن التعليم العالي في السودان شهد نوسعاً ملحوظاً وانتشرت الجامعات في كل ولايات السودان مما انعكس بدورة على زيادة عدد الجامعيين بالمؤسسات و (16\%) من أفراد العينة المبحوثة مستواهم التعليم فوق الجامعي وهي نسبة ضعيفة ومع ذلك لا تتتاسب مع مكانة بنك السودان فهو يحتل مكانـة مرموقة بين البنوك والمؤسسات المصـرفية في السودان بينما بلغت نسبة حملـة

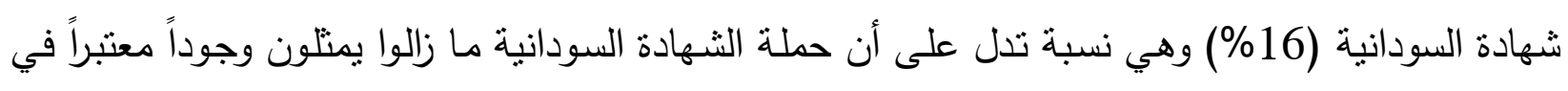
المؤسسات المصرفية وهذا يؤثثر بصورة غير مباشـرة على سير العمل من حيث التأهيل العلمي والكفاءة و المقدرة وقلة الخبرة العلمية. 
ثانياً: البيانات الموضوعية

جدول رقم (3) - (3)

\begin{tabular}{|c|c|c|}
\hline النسبة المئوية\% & التكرار & التخصص العلمي الدقيق \\
\hline$\% 12.0$ & 3 & إعلام \\
\hline$\% 16.0$ & 4 & علاقاتعامة \\
\hline$\% 32.0$ & 8 & إدارة عامة \\
\hline$\% 16.0$ & 4 & اقتصاد \\
\hline$\% 4.0$ & 1 & ق ق \\
\hline$\% 20.0$ & 5 & أخرى \\
\hline$\% 100.0$ & 25 & الهجموع \\
\hline
\end{tabular}

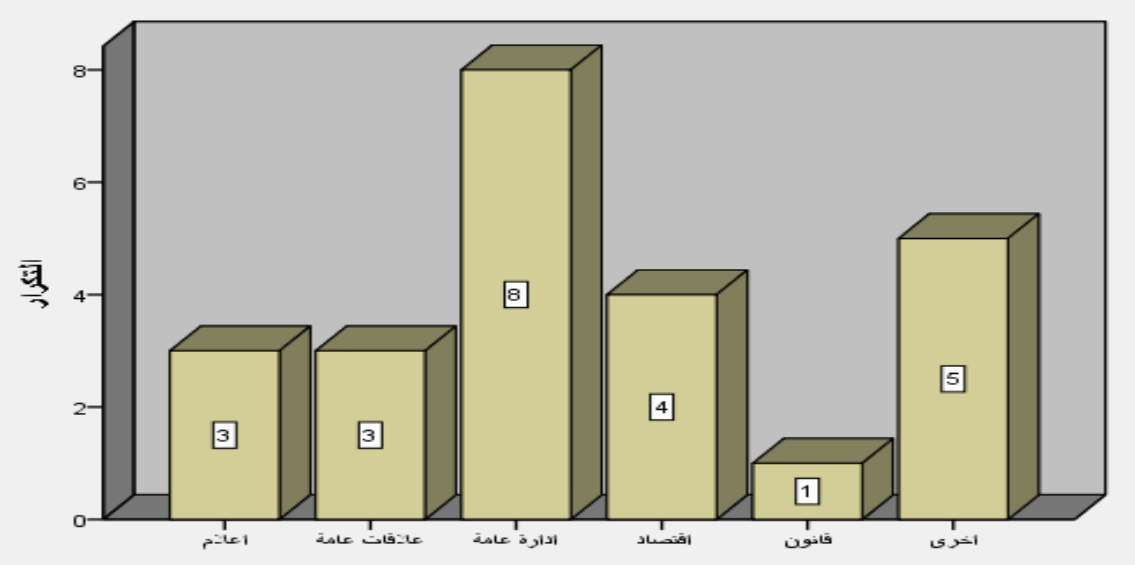

يتضح من الجدول رقم (3) والرسم البياني أعلاه أن (32\%) من أفراد العينة المبحوثة من حملة شهادات في تخصص إدارة عامة و (20\%) من حملة شهادات في تخصصات أخرى مثل بنوك ومصـارف وترجمة عامة ومهندس وهندسة الكترونية أمـا العلاقات العامـة بلغت نسبتها (16\%) فقط والإعـام (12\%) وهذا مؤشر سـلبي يـدعو إلى ضـرورة الالتقـات إلىى تعيبين القـائمين بـالإعلام والعلاقـات العامـة مـن حملـة الثــادات 
فاعلية الأنشطة الاتصالية للعلاقات العامة في تعزيز أداء المؤسسات المصرفية- الرشيد داؤد ادم سليمان ، المعز موده علي مهوده

المتخصصة في العلاقات العامة والإعلام وبلغت نسبة حملة شهادات الاقتصاد (16\%) بينما نسبة حملة شهادات القانون (4\%) من أفراد العينة المبحوثة.

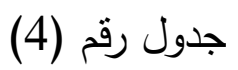

يوضح دور الأنشطة الاتصالية للعلاقات العامة في تطوير أداء بنك السودان المركزي

\begin{tabular}{|c|c|c|}
\hline المئوية النسبة & التكرار & في تطوير أداء بنك اللأنشطة الاتصالية للعلاقات العامة \\
\hline$\% 8.0$ & 2 & لا أوافق \\
\hline$\% 8.0$ & 2 & محايد \\
\hline$\% 36.0$ & 9 & أوافق \\
\hline$\% 48.0$ & 12 & أوافق بشدة \\
\hline$\% 100.0$ & 25 & المجموع \\
\hline
\end{tabular}

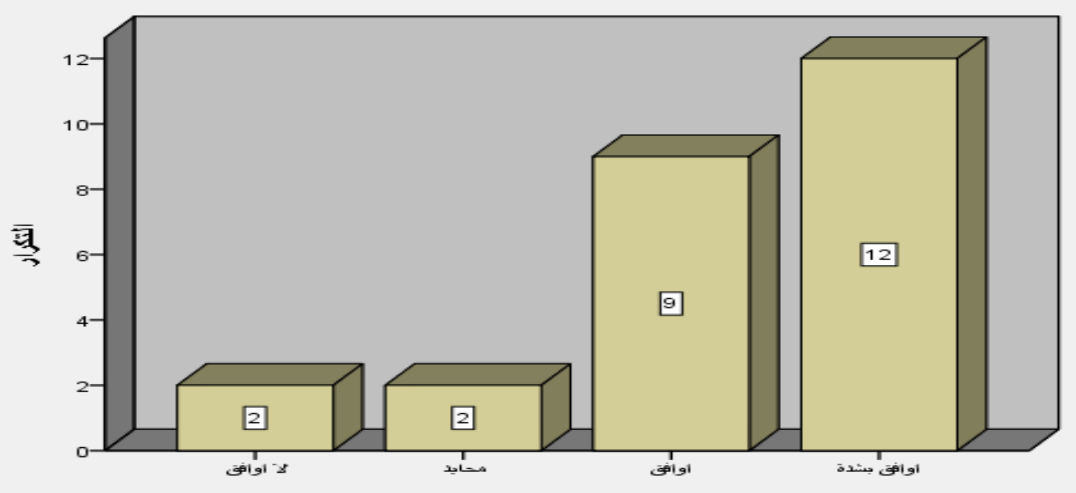

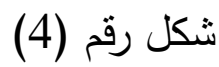

يتضح من الجدول رقم (4) والرسم البياني أعلاه أنه يحتوي على آراء أفراد العينة حول العبارة يوجد دور للأنشطة الاتصـالية للعلاقات العامـة في تطوير أداء بنك السودان حيث معظم أفراد العينة المبحوثة بنسبة (48\%) يوافقون بثدة بأن هنالك دور للأنشطة الاتصالية في تطوير أداء بنك السودان و (36\%) يوافقون أيضاً على ذلك وهذا يعني أن البرامج والأنشطة الاتصالية التي تقوم بها إدارة العلاقات العامة داخل 
وخارج البنك لها دور واضـح فعال في ترقية وتطوير أداء بنك السودان بينما بعضاً من أفراد العينة وبنسبة مئوية (8\%) لا بوافقون.

جدول رقم (5) يوضح التغطيات الإعلامية لأنشطة البنك

\begin{tabular}{|c|c|c|}
\hline المئوية \% النسبة & التكرار & التغطيات الإعلامية \\
\hline$\% 32.0$ & 8 & أوافق بشدة \\
\hline$\% 36.0$ & 9 & أوافق \\
\hline$\% 8.0$ & 2 & محايد \\
\hline$\% 4.0$ & 1 & لا أوافق \\
\hline$\% 20.0$ & 5 & لا أوافق بشدة \\
\hline$\% 100.0$ & 25 & المجموع \\
\hline
\end{tabular}

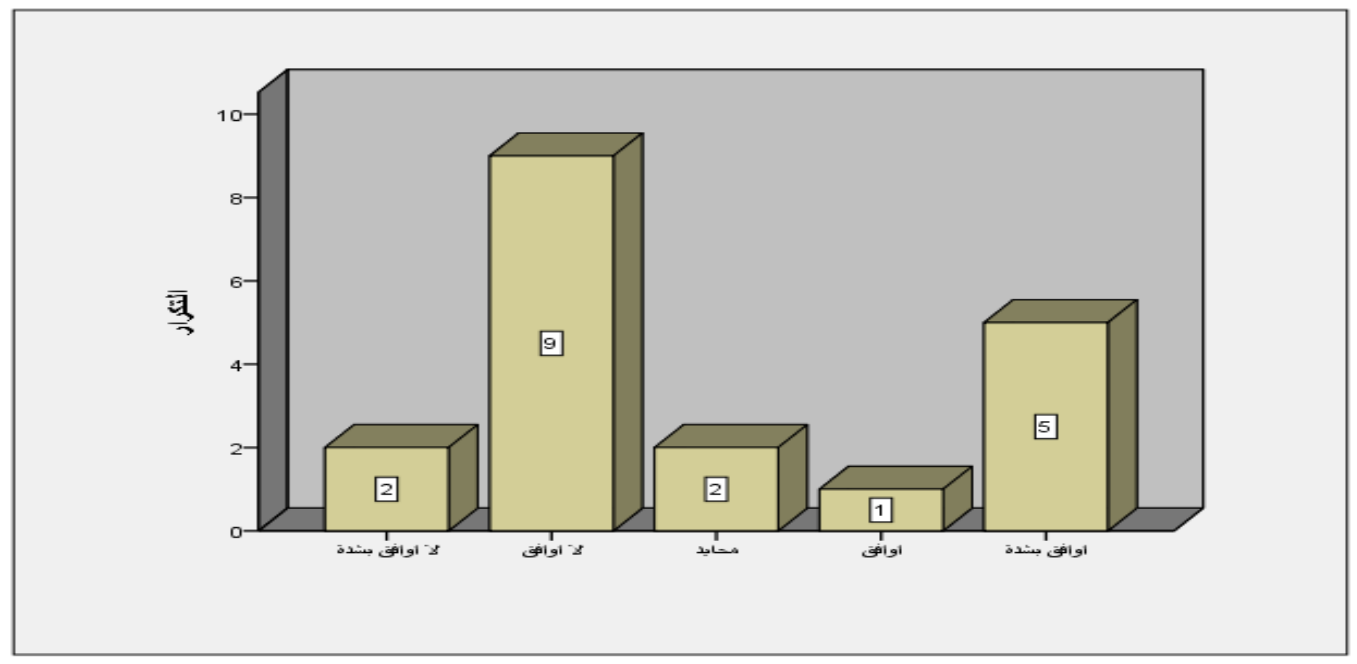

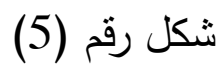

يتضح من الجدول رقم (5) والرسم البياني أعلاه أن بعض أفراد العينة المبحوثة وبنسبة مئوية بلغت (36\%) يوافقون على أن إدارة العلاقـات العامـة ببنـك السـودان تقوم بالتغطيـة الإعلاميـة لأنشـطة البنـلك و (32\%) أيضاً يوافقون على ذلك وبثدة بينما بعض أفراد العينة المبحوثة بنسبة بلغت (20\%) لا يوافقون 
فاعلية الأنشطة الاتصالية للعلاقات العامة في تعزيز أداء المؤسات المصرفية- .الرشيد داؤد ادم سلمان ، المعز مهوده علي موده

على أن إدارة العلاقات العامة تقوم بالتغطية الإعلامية لأنشطة البنك ونسبة (8\%) محايدون وهذا يوضح أن إدارة العلاقات العامة في بنك السودان تقوم بتغطية إعلامية لأنشطة البنك.

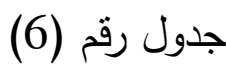

يوضح نوعية الوسائط الاتصالية التي تحرص العلاقات العامة على استخدامها في نشاطها بالبنك

\begin{tabular}{|c|c|c|}
\hline المئوية النسبة & التكرار & ما نوعية الوسائط الاتصالية التي تحرص العلاقات \\
\hline$\% 12.0$ & 3 & الصحف \\
\hline$\% 4.0$ & 1 & الإذاعة \\
\hline$\% 4.0$ & 1 & التلفزيون \\
\hline$\% 44.0$ & 11 & الانترنت \\
\hline$\% 20.0$ & 5 & التلفون \\
\hline$\% 12.0$ & 3 & الهاتف السيار \\
\hline$\% 4.0$ & 1 & قيم مفقودة \\
\hline$\% 100.0$ & 25 & الهجموع \\
\hline
\end{tabular}

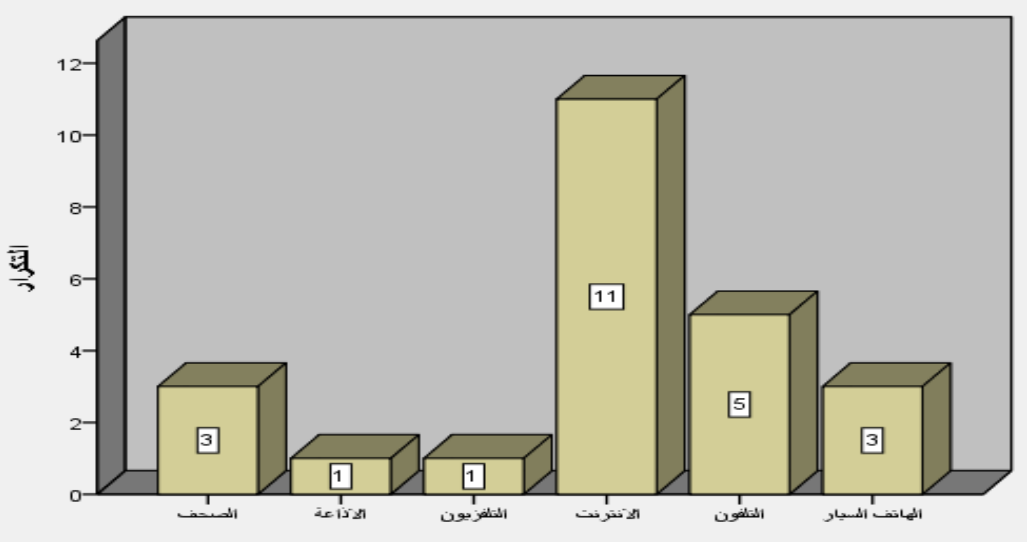

يتضـح من الجدول رقم (3) والرسم البياني أعلاه والذي يحتوي على آراء أفراد العينة حول العبارة

أعلاه (44\%) من المبحوثين يقولون أن الإنترنت هو أكثر الوسائل الاتصالية التي تحرص العلاقات العامة على استخدامها في نشاطها وبعده التلفون بنسبة بلغت (20\%) بينما تساوت الصحف والهاتف السيار بنسبة 
(12\%) لكل وسيلة وأيضاً نساوت نسبة الإذاعة والتلفزيون بنسبة (4\%) كل ذلك يشبر إلى الأهمية النسبية لوسائل الاتصال الجماهيرية التي تحرص إدارة العلاقات العامة على استخدامها في نشاطها بالبنك حيث أنها تركز على استخدام الانترنت أكثر ثم الهاتف السيار ثم الصحف ثم الإذاعة والتلفزيون وهذا يوضح أن البنك يواكب التطور التكنولوجي في مجال وسائل الاتصال التي تستخدمها العلاقات العامة. جدول رقم (7) (1) - (1)

يوضح تتظيم إدارة العلاقات العامة لقاءات دورية بين العاملين والمسؤولين في إطار تبادل المعلومات بصورة مباشرة في البنك

\begin{tabular}{|c|c|c|}
\hline 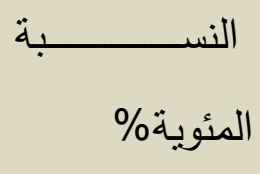 & التكرار & 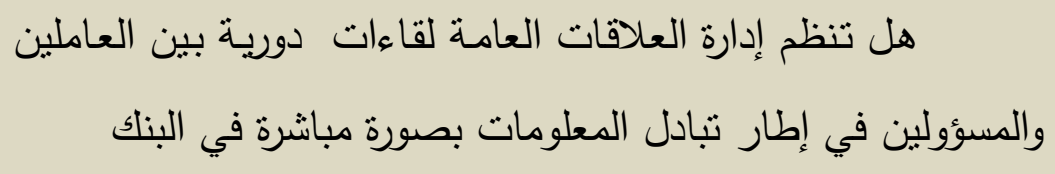 \\
\hline$\% 36.0$ & 9 & نعم \\
\hline$\% 16.0$ & 4 & أحياناً \\
\hline$\% 48.0$ & 12 & y \\
\hline$\% 100.0$ & 25 & المجموع \\
\hline
\end{tabular}

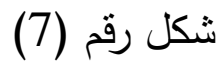

يتضح من الجدول رقم (7) والرسم البياني أعلاه والذي يوضح آراء أفراد العينة حول العبارات أعلاه أن معظم أفراد العينة المبحوثة وبنسبة مئوية بلغت (48\%) كانت إجاباتهم لا بينما بعضهم يقولون نعم بنسبة بلغت (36) من أفراد العينة وآخرون يشيرون إلى أحياناً بنسبة مئوية (16\%) وهذا يدل على أن علاقات العامة لا تتظم لقاءات دورية بين العاملين والمسئولين في إطار تبادل المعلومات بصورة مباشرة في البنك. النتائج الدراسة: 1- أثنتت نتائج الدراسـة أن الأنشطة الاتصالية التي تقوم بها إدارة العلاقات العامـة داخل وخارج بنك السودان لها دور واضح وفعال في نطوير أداء البنك.

2- أكدت الدراسة أن إدارة العلاقات العامة في بنك السودان تقوم بالتغطية إعلامية لأنشطة البنك. 3- أثتبت نتائج الدراسـة أن علاقات العامـة لا تنظم لقاءات دوريـة بين العاملين والمسئولين في إطـار تبادل المعلومات بصورة مباشرة في البنك. 
4- أكدت الدراسـة أن الإنترنت هو أكثر الوسـائل الاتصـالية التي تحرص إدارة العلاقات العامـة على استخدامها في نشاطها وبعده الهاتف السيار ثم الصحف ثم الإذاعة والتلفزيون.

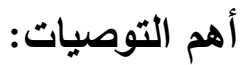

1) فصل إدارة العلاقات العامة من إدارة الخدمات وجعلها إدارة مستقلة قائمة بذاتها تتبع للإدارة العليا

للبناك.

2) إعطاء صـلاحيات أكبر لإدارة العلاقات العامـة حتى تتـارك الإدارة العليا في صنع القرار وحل المشاكل والصعوبات والأزمات التي تواجه البنك.

3) يجب علي إدارة العلاقات العامة أن تنظم لقاءات دورية بين العاملين والمسؤولين في إطار تبادل المعلومات بصورة مباشر بينهم.

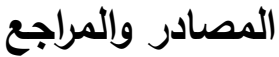

1- علي عجوه، العلاقات العامة في المنشآت المالية،ط2، (القاهرة: عالم الكتب, 1999م) ص11. 2- عجوة،علي, 2001م العلاقات العامة بين النظرية والتطبيق القاهرة: عالم الكتب. 3-شلبي،كرم،1989م، معجم المصطلحات الإعلامية، ط1، دار الثروق للنشر . 4- البخشوني، أحمد عبدالحارث، 2001م، العلاقات العامة منظور الخدمة الاجتماعية، بطال إسكندرية. 5- عجوة، علي، 2004م الأسس العلمية للعلاقات العامة، ط4، القاهرة: عالم الكتب.

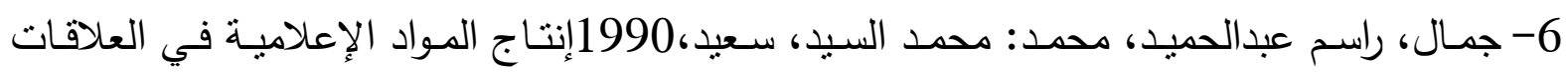
العامة، ط1، جدة مكتبة مصباح.

7- إمام، إبراهيم، 1958، فن العلاقات العامة، ط1، القاهرة مكتبهة العنة الانجلوا. 8- العالم، صفوت، إلم، 2002م، فنون العلاقات العامة، ط1، القاهرة: دار الهاني للطباعة والنشر . 9- خير الدين،حسن محمد،2003م، العلاقات العامة المبادئ والتطبيق، ط1 القاهرة: مكتبة عين شمس. 9 - المصري، حمد محمد،2002م، العلاقات العامة الإسكندرية: مؤسسة شباب الجماعة.

10 -الصوفي، خالد، 2004م، العلاقات العامـة أساليب وممارسات، القاهرة: دار الكتب العلمية للنشر الإسر

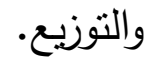

11-عباس، نـوال حسين، 2003م، المؤسسـات الماليـة ط1، الخرطوم: شـركة مطابع السودان للعملـة

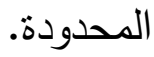
-12 - عثمان إبراهيم، 2005م، الاقتصادي السوداني، ط1، أم درمان، دار القرآن الكريم للطباعة. 
13- حسن أحمد الخضري، 1410هـ، البنوك الإسلامية ط1، القاهرة: دار الحرية للطباعة.

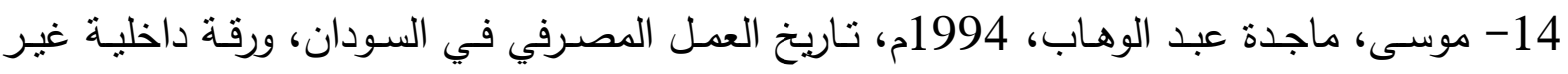

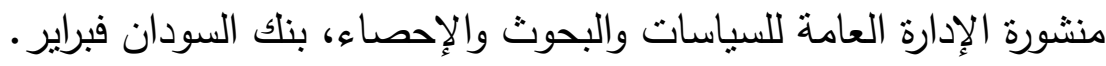

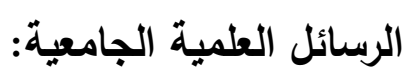
15 - صالح بابكر الحاج، دور العلاقات العامة في تطوير المصارف الإسلامية، رسالة دكتوراه غير منشورة

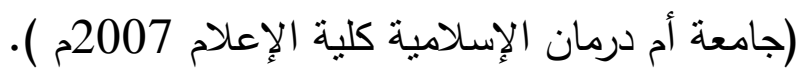

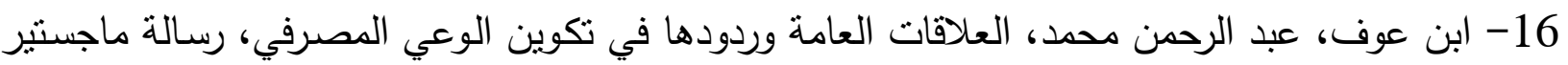
غير منشورة (جامعة أم درمان الإسلامية،كلية الإعلام 2007م). 